\title{
Impact of the introduction of a nucleic acid amplification test for Clostridium difficile diagnosis on stool rejection policies
}

\author{
J. Goret ${ }^{1}$, J. Blanchi' ${ }^{1}$ P. Floch ${ }^{2}$, O. Peuchant ${ }^{2}$, D. Chrisment ${ }^{3}$, R. Sanchez ${ }^{4}$, H. Biessy ${ }^{5}$, R. Lemarié ${ }^{5}$, D. Leyssene ${ }^{6}$, \\ B. Loutfi7 , S. Mimouni ${ }^{8}$, T. Flao ${ }^{9}$, C. Bébéar ${ }^{7}$ and F. Mégraud ${ }^{1 *}$ (D)
}

\begin{abstract}
Background: The change from non-molecular to nucleic acid amplification tests (NAATs) is known to increase the detection of Clostridium difficile infection (CDI); however, the impact on stool rejection policies in clinical laboratories is unclear. The current guidelines have reinforced the importance of respecting strict conditions for performing tests on stool samples for CDI diagnosis. The purpose of this study was to estimate whether the implementation of molecular tests has resulted in changes in stool rejection policies between clinical laboratories that introduced NAATs and those that did not.
\end{abstract}

Results: A survey was conducted to evaluate the change in the number of stool samples rejected and the rejection criteria among 12 hospital laboratories in southwestern France before and after the switch from non-molecular tests to NAATs using retrospective data from June 1 till September 30, 2013 and the same period 2014. Four laboratories introduced NAATs as a second or third step in the process. A total of 1378 and 1297 stools samples were collected in 2013 and 2014, respectively. The mean number of rejected stool samples significantly increased $(p<0.001$, Chi square test), with a total of 99 (7.1\%) and 147 (11.3\%) specimens rejected in 2013 and 2014, respectively. Notably, these laboratories had more stringent criteria and were no longer testing the stool samples of patients with CDI-positive results within 7 days. In contrast, there was a significant decrease in the rate of rejected stool samples $(p<0.001$, Chi square test) in the five laboratories that did not adopt NAATs and a less stringent stool rejection policy.

Conclusion: Nucleic acid amplification test implementation improved compliance with recommended stool rejection policies. Laboratories should follow the recommended laboratory algorithm for the CDI diagnosis combined with the correct stool rejection policy.

Keywords: C. difficile, Diagnosis, Impact, Molecular, Algorithm, NAAT

\section{Background}

Clostridium difficile infection (CDI) is currently the major cause of healthcare-associated diarrhea. Multiple diagnostic approaches are available for CDI. No single test is suitable for use as a stand-alone test, and current Infectious Disease Society of America (IDSA) and European Society of Clinical Microbiology and

\footnotetext{
*Correspondence: francis.megraud@chu-bordeaux.fr

${ }^{1}$ Laboratoire de Bactériologie, C.H.U. de Bordeaux, Groupe Hospitalier

Pellegrin, Place Amélie Raba Léon, 33076 Bordeaux Cedex, France

Full list of author information is available at the end of the article
}

Infectious Diseases (ESCMID) guidelines [1-3] recommend combining two tests in an algorithm to optimize the diagnosis. Despite its poor sensitivity when compared to toxigenic culture (60-81\%) [4], toxin enzyme immunoassay (EIA) remains the preferred method for primary diagnosis in most laboratories because of its low cost and short turnaround time. In 2014, the results of a European multicenter prospective point-prevalence study of CDI in hospitalized patients with diarrhea highlighted the poor performances of the tests used in clinical laboratories [5], these poor performances being responsible for $25 \%$ of misdiagnoses. 
To overcome this problem, nucleic acid amplification tests (NAATs) have been developed and are increasingly adopted. They are reported to have sensitivities ranging from 84 to $94 \%$ and short turnaround times compared with toxigenic culture [1]. Changing from EIA to more sensitive molecular tests is reported to increase the CDI detection during the transition year, with an increase up to $57 \%[4,6-12]$. The increased sensitivity of molecular tests has improved the laboratory detection of CDI cases, and current guidelines recommend their use in diagnosis as the first or second step [3]. However, a molecular test is difficult to implement in clinical laboratories because of its costs, the potential for confusion by physicians and overuse because of its novelty. It also cannot differentiate a truly infected patient from a colonized one $[6,13]$. Its diagnostic accuracy is also variable and depends on CDI prevalence [14].

To increase the diagnostic accuracy of CDI, European guidelines have reinforced the importance of respecting strict conditions for performing tests on stool samples [2, $3]$. Unformed stool samples from patients aged 3 years or older should be tested, and formed stool samples must be rejected [3]. Tests should be performed after at least 3 days in the hospital or after antibiotic treatment [2]. They should not have to be repeated within 7 days if they were positive and no test of cure is needed [15-17]. CDI testing should not be limited to samples with a specific physician's request. Davies et al. [5] highlighted that over a third of laboratories detect $C$. difficile only upon a physician's request. Dubberke et al. [18] showed that this request was inadequate, with $36 \%$ of the requests for non-diarrheal stools and $19 \%$ after laxative administration. Selection of the stool samples at the clinical laboratory level should improve the accuracy of the CDI diagnosis. However, it is unclear how closely the clinical laboratories follow these guidelines and whether they have an adequate stool sample rejection policy. The rate of rejected stool samples was reported to increase after NAAT implementation [6].

The purpose of this study was to estimate whether the implementation of NAATs resulted in changes in stool rejection policies between clinical laboratories that introduced NAATs and those that did not, between 2013 and 2014, in southwestern France. The stool rejection criteria and impact on the CDI positivity rate were determined. The correlation between a positive molecular test and a real case of CDI was also evaluated.

\section{Methods}

A multicenter comparative retrospective survey was conducted in October 2014 in 12 clinical laboratories from hospitals in southwestern France. The laboratories provided hospital institutional data (size and type of institution) and details of current CDI laboratory diagnostic methods.

We compared the stool rejection policy of laboratories that introduced NAATs to that of laboratories that did not, between June 1 to September 30, 2013 and June 1 to September 30, 2014. A laboratory that introduced NAATs was defined as a laboratory using a novel molecular test in the first, second or third line of a diagnostic algorithm since October 2013. A laboratory without NAATs was defined as a laboratory using a non-molecular test such as EIA for toxins, EIA for glutamate dehydrogenase $(\mathrm{GDH})$ and/or culture with toxin detection, and EIA detection of strains, alone or combined into algorithms.

The submitted survey included routine tests, the number of stools collected, the number of stools tested, the number of CDI-positive results, the number of tested patients and the stool rejection policy during the two periods. A positive result was defined as a positive test for free toxins or toxin genes. The positivity rate was defined as the ratio of positive stool samples to the total number of tested stools. The stool rejection rate was defined as the ratio of the number of tested stools to the total number of stool samples received at the laboratories. The repetition of the tests was evaluated by the number of tests performed per patient. The request criteria for performing tests were the following: only upon physician's request, on all stool samples, on all diarrheal stool samples, on formed stool samples, for a patient 3 years or younger, for all patients 65 years or older, for patients hospitalized for a minimum of 3 days, on stool samples collected for $48 \mathrm{~h}$ or more, after a first positive sample during the same diarrheal episode, after a first negative sample during the same diarrheal episode, after a first positive sample within 7 days and for a test of cure.

The Chi square statistical test was used to assess differences.

To differentiate patients with CDI from asymptomatic carriers, we assessed whether the clinical picture of patients with a positive toxin-gene result met the criteria of CDI defined by Debast et al. [19]: significant diarrhea, ileus, toxic megacolon or pseudomembranous colitis.

\section{Results}

Ten of the 12 requested laboratories answered the survey. Data from one laboratory were not included because of the introduction of a molecular test before 2013. The clinical laboratories included were from eight medium size $[100,000-500,000$ patient bed days (pbds)] and one large size ( $>500,000$ pbds) hospitals. Between June 1 and September 30, 2013, none of the laboratories from these nine hospitals performed molecular tests for CDI diagnosis (Table 1), instead they used a one- to three-step 
algorithm including GDH EIA, toxin EIA and toxigenic culture with toxin EIA detection of strains. After October 2013, four of the nine laboratories introduced NAAT in a two-step algorithm consisting of a screening test by GDH EIA (ImmunoCard ${ }^{\circledR}$ C. difficile GDH, Meridian, Cincinnati, OH, USA) followed by a NAAT (illumigene ${ }^{\circledR}$, Meridian) for confirmation. A significant increase in the stool sample rejection rate was observed (Table 1) from 7.1 in 2013 to $11.3 \%$ in 2014 ( $\mathrm{p}<0.001)$. In contrast, in the five laboratories that did not adopt NAATs, the overall rate of rejected stool samples decreased from 11.7\% in 2013 to $6.1 \%$ in $2014(\mathrm{p}<0.001)$. Among these five laboratories, one observed a significant increase in the rejection rate $(\mathrm{E})$, two others did not reject any samples in both periods ( $\mathrm{F}$ and $\mathrm{H}$ ), and two noted a decrease in the rejection rate ( $\mathrm{G}$ and $\mathrm{I})$. Among the laboratories that introduced NAATs, the rate of CDI-positive results was not significantly different $(\mathrm{p}=0.07)$, except for one laboratory $(\mathrm{B})$ (Table 1$)$ that performed the largest number of tests $(p=0.003)$. In this laboratory, the positivity rate increased from 4.1 to $8.1 \%$. No significant difference in the percentage of positive results was found in laboratories that did not introduce NAATs. Overall, there was no change in the mean number of stool samples tested globally or per patient (Additional file 1: Table S1) in the two groups of laboratories.
In 2014, the laboratories that introduced NAATs were no longer limiting their $C$. difficile detection only to physicians' requests; they performed tests on stools from all patients hospitalized for 3 days with diarrhea and no longer tested the stool samples of patients with a positive CDI result obtained within 7 days (Additional file 2: Table S2). The B laboratory was also the only one to test all diarrheal stool samples collected. The laboratories that did not implement NAATs did not adopt these criteria in 2014, and two of them performed tests on all collected samples. There was no change in their stool rejection policy between the two periods.

The correlation between positive NAATs and the clinical picture was evaluated. Seventy of 73 patients (95.8\%) who had a positive NAAT result had a clinical picture consistent with CDI in terms of the ESCMID criteria (Table 2).

\section{Discussion}

The clinical laboratories that introduced NAATs showed a significantly increase in the rate of rejected stool samples. Previously, Cohen et al. [6] reported that laboratories adopted a more stringent stool rejection policy after NAAT implementation in the USA. These authors did not specifically ask laboratories to explain the rationale for adopting more stringent policies, and no studies were conducted to evaluate the stool rejection criteria

Table 1 Change in the number of stool specimens tested for C. difficile and the rate of positive specimens according to the laboratories between 2013 and 2014

\begin{tabular}{|c|c|c|c|c|c|c|c|c|}
\hline \multirow[t]{2}{*}{ Laboratory } & \multicolumn{2}{|c|}{ Testing algorithm } & \multicolumn{3}{|c|}{ Number of rejected samples } & \multicolumn{3}{|c|}{ Number of positive results } \\
\hline & 2013 & 2014 & 2013 & 2014 & $p$ & 2013 & 2014 & $\mathrm{p}$ \\
\hline A & $\mathrm{GDH}+\mathrm{EIA}^{\mathrm{a}}$ & $\mathrm{GDH}+\mathrm{NAAT} \mathrm{T}^{\mathrm{d}}$ & 10/133 (7.5) & $34 / 137(24.8)$ & $<0.001$ & $9 / 123(7.3)$ & 10/103 (9.7) & 0.52 \\
\hline B & $\mathrm{GDH}+\mathrm{EIA}^{\mathrm{b}}$ & $\mathrm{GDH}+\mathrm{NAAT} \mathrm{T}^{\mathrm{d}}$ & $89 / 776(11.5)$ & $83 / 653(12.7)$ & 0.47 & $29 / 687(4.1)$ & $46 / 570(8.1)$ & 0.003 \\
\hline C & $\mathrm{GDH}+\mathrm{EIA}^{\mathrm{b}}$ & $\mathrm{GDH}+\mathrm{NAAT} \mathrm{T}^{\mathrm{d}}$ & $0 / 244(0.0)$ & 30/314 (9.6) & $<0.001$ & 21/244 (8.6) & $20 / 284(7.0)$ & 0.50 \\
\hline D & $\mathrm{GDH}+\mathrm{EIA}^{\mathrm{b}}+\mathrm{TC}$ & $\mathrm{GDH}+\mathrm{NAAT}^{\mathrm{d}}$ & 0/225 (0.0) & 0/193 (0.0) & * & $18 / 225(8.0)$ & 14/193 (7.3) & 0.77 \\
\hline Total & & & $99 / 1378(7.1)$ & 147/1297 (11.3) & $<0.001$ & $77 / 1279(6.0)$ & $90 / 1150(7.8)$ & 0.07 \\
\hline E & $E I A^{c}$ & $\mathrm{GDH}+\mathrm{EIA}^{\mathrm{a}}$ & $6 / 42(14.2)$ & 13/44 (29.5) & 0.88 & $2 / 42(4.7)$ & 6/31 (19.4) & 0.09 \\
\hline $\mathrm{F}$ & $\mathrm{GDH}+\mathrm{EIA}^{\mathrm{b}}$ & $\mathrm{GDH}+\mathrm{EIA}^{\mathrm{b}}$ & $0 / 73(0.0)$ & $0 / 85(0.0)$ & * & 6/73 (8.2) & $4 / 85(4.7)$ & 0.37 \\
\hline G & $G D H+E I A^{b}$ & $\mathrm{GDH}+\mathrm{EIA}^{\mathrm{b}}$ & 47/178 (26.4) & 25/152 (16.4) & 0.82 & 20/147 (13.6) & $17 / 127(13.4)$ & 0.96 \\
\hline $\mathrm{H}$ & $\mathrm{GDH}+\mathrm{EIA}^{\mathrm{b}}+\mathrm{TC}$ & $\mathrm{GDH}+\mathrm{EIA}^{\mathrm{b}}+\mathrm{TC}$ & 0/228 (0.0) & $0 / 267(0.0)$ & * & $12 / 228(5.3)$ & 8/267 (3.0) & 0.20 \\
\hline । & $\mathrm{GDH}+\mathrm{EIA}^{\mathrm{b}}+\mathrm{TC}$ & $\mathrm{GDH}+\mathrm{EIA}^{\mathrm{b}}+\mathrm{TC}$ & 23/211 (10.9) & $5 / 162(3.1)$ & 0.008 & 17/188 (9.0) & 11/157 (7.0) & 0.49 \\
\hline Total & & & 76/648 (11.7) & $43 / 710(6.1)$ & $<0.001$ & $57 / 678(8.4)$ & 46/667 (6.9) & 0.30 \\
\hline
\end{tabular}

The number of rejected samples is expressed as the number of samples rejected/total number of samples collected (percent). The number of $C$. difficille infection (CDI)-positive samples is expressed as the number of CDI-positive samples/total number of samples tested (percent). The number of tests per patient is expressed as the number of tested samples/number of patients (ratio). A to D, laboratories that introduced nucleic acid amplification tests (NAATs). E to $I$, laboratories that did not introduce NAATs

GDH glutamate dehydrogenase by enzyme immunoassay, EIA toxin enzyme immunoassay, TC toxigenic culture

Statistical analysis was performed using the Chi square test. A p value $<0.05$ was considered significant

*Not applicable

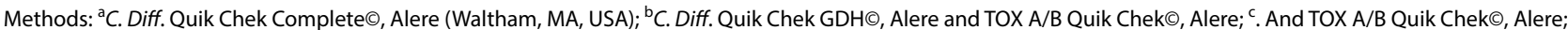
${ }^{\mathrm{d} I m m u n o C a r d}{ }^{\circledR}$ C. difficile GDH, Meridian (Cincinnati, OH, USA) and NAAT illumigene ${ }^{\circledR}$, Mridiane 
adopted in European laboratories after implementation of a new testing algorithm for CDI diagnosis. In our study, three criteria based on the current diagnosis recommendations [2] were adopted by the NAAT laboratories: they no longer limited their $C$. difficile detection to physicians' requests, they performed tests on patients hospitalized for a minimum of 3 days with diarrhea and they no longer tested the stool samples of patients with a positive CDI result obtained within 7 days. The possibility for the microbiology laboratory to cancel repeat tests within 1 week is thought to have contributed to a significant decrease in the number of tested stools [7]. A reduction in the number of tested samples from 48 to $38.2 \%$ was previously reported after NAAT implementation $[6$, $7,20]$. This reduction was not observed in our study. The number of stool samples tested per patient was stable, highlighting that the laboratories controlled the number of tests and limited the overuse of NAATs (Additional file 1: Table S1). The cancellation of repeated tests should be considered as a priority by clinical laboratories, but we cannot conclude that only one criterion is needed for effective action. The laboratories must adopt all of the stool rejection recommendations [1-3] to improve CDI diagnosis.

The use of suboptimal clinical tests for CDI diagnosis is still prevalent throughout Europe [5, 21, 22]. Both the IDSA [1] and ESCMID [2, 3] suggest a GDH EIA-based two-step algorithm or use of NAAT alone to improve diagnostic accuracy. The French guidelines at the time, did not include these diagnosis algorithms [23], which were added to the revised guidelines in 2015. Only one laboratory used toxin EIA alone in 2013, while the others used two- or three-step algorithms. In 2014, all of the laboratories (100\%) chose a recommended two- or threestep algorithm [2] with an initial screening by GDH EIA, which is superior to the 65 and 85\% reported in France and the UK, respectively, in 2015 [24]. The tests were all

\begin{tabular}{|c|c|c|c|}
\hline Laboratory & $\begin{array}{l}\text { Number of positive } \\
\text { NAAT results }\end{array}$ & $\begin{array}{l}\text { Number } \\
\text { of patients }\end{array}$ & $\begin{array}{l}\text { Chart review } \\
\text { in favor of CDI }\end{array}$ \\
\hline A & 10 & 9 & $9(100.0 \%)$ \\
\hline B & 46 & 41 & 39 (95.1\%) \\
\hline C & 20 & 15 & 14 (93.3\%) \\
\hline D & 14 & 8 & $8(100.0 \%)$ \\
\hline Total & 90 & 73 & 70 (95.8\%) \\
\hline
\end{tabular}

The chart review was based on the clinical definition of $C$. difficile infection in the ESCMID recommendations [1] performed the day the stool samples were received by the laboratories. The current guidelines for CDI laboratory diagnosis [2] were adopted in southwestern France. PCR alone was described to be more sensitive than the GDH EIA-based algorithm, but the data are conflicting [4, 25, 26]; laboratories chose the two-step algorithm because of its lower cost per patient. Although the laboratories that did not implement NAATs used the recommended testing algorithm, they did not follow the recommendations carefully and had a poor stool rejection policy. Greater efforts to improve stool rejection policies are necessary.

The rate of positive results increased significantly for only one laboratory that introduced NAATs and performed the largest number of tests. Previous studies described an increase in CDI-positive results of up to $57 \%$ with PCR testing alone [7, 8, 10-12, 20], and this increase was expected for all laboratories that implemented NAATs but was only observed for laboratory B (Table 1). In Europe, the mean annual CDI testing and CDI-positive rates were reported to be significantly higher in medium-sized hospitals (46.2/10,000 and $3.3 / 10,000$ pbds, respectively) compared to large hospitals $(28.6 / 10,000$ and $1.5 / 10,000$ pbds, respectively) [24]. The incidence of CDI in France ranges from 2.9 to 3.6 cases/10,000 pbds [24, 27]. In contrast, Cohen et al. did not observe a systematic increase in positivity rates after the implementation of a multistep algorithm involving NAATs [6]. The enrollment of patients, the low level of awareness of physicians and the seasonal pattern of the incidence of CDI could explain our results in the medium-sized hospitals [28-31]. The relatively low number of specimens processed by these laboratories and our short observation period could also explain these results. Regarding the positivity rate, the study has several limitations: this is a nonrandomized and retrospective study that included a network of different sized hospitals.

Concerns about the detection of colonized patients using NAAT have been raised and emphasize the importance of testing patients with clinically significant diarrhea in order to avoid false-positive tests. We assessed whether the clinical picture of patients with a positive toxin-gene result met the criteria of CDI defined by Debast et al. [19]. Planche et al. [13] suggested that the presence of free toxins could best define true or severe CDI. The presence of free toxins was significantly associated with unfavorable CDI, with an increase in white blood cells and a higher mortality rate. Using the clinical criteria defined by the European recommendations [9], there was a strong correlation between CDI-positive NAAT results and the clinical picture. The Meridian algorithm (EIA ImmunoCard ${ }^{\circledR} C$. difficile GDH, followed by NAAT illumigene ${ }^{\circledR}$ for toxin 
gene), along with an adequate stool rejection policy, provided a true CDI diagnosis.

\section{Conclusion}

Clinical laboratories will continue to adopt NAATs as part of their routine testing methods due to the higher sensitivity and short turnaround time of these tests. This is the first report on the impact of the implementation of NAATs on stool rejection policies in Europe. The clinical laboratories took advantage of the change in the testing algorithm including NAATs to adopt the current recommendations. The current European guidelines have to be followed combined with by a correct stool rejection policy. The adoption of the largest number of the recommended criteria is necessary to have an effective rejection policy. An increase in the rate of rejected stool samples was observed because hospitals no longer limited their $C$. difficile detection upon physicians' requests only and furthermore they limited repeat tests. NAAT implementation will likely improve compliance with recommended stool rejection policies and improve detection of $C$. difficile.

\section{Additional files}

Additional file 1: Table S1. Change in the number of stool specimens tested per patient expressed as a ratio of the number of tested samples/ number of patients. Statistical analysis was performed using the Chi square test. p value $<0.05$ was considered significant. ${ }^{*}$ Not applicable.

Additional file 2: Table S2. Change in the stool rejection policy according to the laboratories between 2013 and 2014. Data are the number of laboratories that adopted the requested criteria for performing tests among the four laboratories that introduced nucleic acid amplification tests (NAATs) and the five that did not introduce NAATs, between the studied periods.

\section{Authors' contributions}

$J G$, JB and FM conceived the study and wrote the article. JG and JB coordinated the survey, collected the data and carried out the analysis. FP, OP, DC, $\mathrm{RS}, \mathrm{HB}, \mathrm{RL}, \mathrm{DL}, \mathrm{BL}, \mathrm{SM}$ and TF answered to the survey and collected the data in each included laboratory. They read and corrected the manuscript. All authors read and approved the final manuscript.

\section{Authors' information}

This study was presented at the 25th European Congress of Clinical Microbiology and Infectious Diseases (ECCMID). 25-28 April 2015. Copenhagen, Denmark. JG was a recipient of an ECCMID Travel Grant 2015 for this work. The manuscript was edited for proper English language, grammar, punctuation, spelling, and overall style by one or more of the highly qualified native English-speaking editors at American Journal Experts (6E65-F836-8CCF-406C-DF44).

\section{Author details}

${ }^{1}$ Laboratoire de Bactériologie, C.H.U. de Bordeaux, Groupe Hospitalier Pellegrin, Place Amélie Raba Léon, 33076 Bordeaux Cedex, France. ${ }^{2}$ C.H.U. de Bordeaux, Hôpital Haut-Lévèque, Pessac, France. ${ }^{3}$ C.H. de Dax-Côte d'Argent, Dax, France. ${ }^{4} \mathrm{C} . \mathrm{H}$. de Périgueux, Périgueux, France. ${ }^{5} \mathrm{G}$.H. de La Rochelle-RéAunis, La Rochelle, France. ${ }^{6}$ C. H. de la Côte Basque, Bayonne, France. ${ }^{7}$ C.H.
Mont de Marsan, Mont de Marsan, France. ${ }^{8}$ C. H. Arcachon, Arcachon, France. ${ }^{9}$ C.H.I.C Marmande-Tonneins, Marmande, France.

\section{Acknowledgements}

Not applicable.

Competing interests

The authors declare that they have no competing interests.

Availability of data and materials

Not applicable.

Consent for publication

Not applicable.

Ethics approval and consent to participate

Not applicable.

Funding

None.

\section{Publisher's Note}

Springer Nature remains neutral with regard to jurisdictional claims in published maps and institutional affiliations.

Received: 1 March 2018 Accepted: 19 May 2018

Published online: 30 May 2018

\section{References}

1. Cohen SH, Gerding DN, Johnson S, Kelly CP, Loo VG, MCDonald LC, Pepin J, Wilcox MH. Clinical practice guidelines for Clostridium difficile infection in adults: 2010 update by the society for healthcare epidemiology of America (SHEA) and the infectious diseases society of America (IDSA). Infect Control Hosp Epidemiol. 2010;31(5):431-55.

2. Crobach MJ, Dekkers OM, Wilcox MH, Kuijper EJ. European Society of Clinical Microbiology and Infectious Diseases (ESCMID): data review and recommendations for diagnosing Clostridium difficile-infection (CDI). Clin Microbiol Infect. 2009;15(12):1053-66.

3. Crobach MJ, Planche T, Eckert C, Barbut F, Terveer EM, Dekkers OM, Wilcox $\mathrm{MH}$, Kuijper EJ. European Society of Clinical Microbiology and Infectious Diseases: update of the diagnostic guidance document for Clostridium difficile infection. Clin Microbiol Infect. 2016;22(Suppl 4):S63-81.

4. Eastwood K, Else P, Charlett A, Wilcox M. Comparison of nine commercially available Clostridium difficile toxin detection assays, a real-time PCR assay for $C$. difficile $t c d B$, and a glutamate dehydrogenase detection assay to cytotoxin testing and cytotoxigenic culture methods. J Clin Microbiol. 2009:47(10):3211-7.

5. Davies KA, Longshaw CM, Davis GL, Bouza E, Barbut F, Barna Z, Delmee M, Fitzpatrick F, Ivanova K, Kuijper E, et al. Underdiagnosis of Clostridium difficile across Europe: the European, multicentre, prospective, biannual, point-prevalence study of Clostridium difficile infection in hospitalised patients with diarrhoea (EUCLID). Lancet Infect Dis. 2014;14(12):1208-19.

6. Cohen J, Limbago B, Dumyati G, Holzbauer S, Johnston H, Perlmutter R, Dunn J, Nadle J, Lyons C, Phipps E, et al. Impact of changes in Clostridium difficile testing practices on stool rejection policies and C. difficile positivity rates across multiple laboratories in the United States. J Clin Microbiol. 2014;52(2):632-4.

7. Grein JD, Ochner M, Hoang H, Jin A, Morgan MA, Murthy AR. Comparison of testing approaches for Clostridium difficile infection at a large community hospital. Clin Microbiol Infect. 2014;20(1):65-9.

8. Fong KS, Fatica C, Hall G, Procop G, Schindler S, Gordon SM, Fraser TG. Impact of PCR testing for Clostridium difficile on incident rates and potential on public reporting: is the playing field level? Infect Control Hosp Epidemiol. 2011;32(9):932-3.

9. Goldenberg SD, Price NM, Tucker D, Wade P, French GL. Mandatory reporting and improvements in diagnosing Clostridium difficile infection: an incompatible dichotomy? J Infect. 2011;62(5):363-70. 
10. Longtin Y, Trottier S, Brochu G, Paquet-Bolduc B, Garenc C, Loungnarath $\checkmark$, Beaulieu C, Goulet D, Longtin J. Impact of the type of diagnostic assay on Clostridium difficile infection and complication rates in a mandatory reporting program. Clin Infect Dis. 2013;56(1):67-73.

11. Moehring RW, Lofgren ET, Anderson DJ. Impact of change to molecular testing for Clostridium difficile infection on healthcare facility-associated incidence rates. Infect Control Hosp Epidemiol. 2013;34(10):1055-61.

12. Tartof SY, Yu KC, Wei R, Tseng HF, Jacobsen SJ, Rieg GK. Incidence of polymerase chain reaction-diagnosed Clostridium difficile in a large high-risk cohort, 2011-2012. Mayo Clin Proc. 2014;89(9):1229-38.

13. Planche TD, Davies KA, Coen PG, Finney JM, Monahan IM, Morris KA, O'Connor L, Oakley SJ, Pope CF, Wren MW, et al. Differences in outcome according to Clostridium difficile testing method: a prospective multicentre diagnostic validation study of $C$. difficile infection. Lancet Infect Dis. 2013;13(11):936-45.

14. Deshpande A, Pasupuleti V, Rolston DD, Jain A, Deshpande N, Pant C, Hernandez AV. Diagnostic accuracy of real-time polymerase chain reaction in detection of Clostridium difficile in the stool samples of patients with suspected Clostridium difficile Infection: a meta-analysis. Clin Infect Dis. 2011;53(7):e81-90.

15. Cardona DM, Rand KH. Evaluation of repeat Clostridium difficile enzyme immunoassay testing. J Clin Microbiol. 2008;46(11):3686-9.

16. Mohan SS, McDermott BP, Parchuri S, Cunha BA. Lack of value of repeat stool testing for Clostridium difficile toxin. Am J Med. 2006;119(4):356 e357-358 e357.

17. Nemat $H$, Khan $R$, Ashraf MS, Matta M, Ahmed S, Edwards BT, Hussain R, Lesser M, Pekmezaris R, Dlugacz Y, et al. Diagnostic value of repeated enzyme immunoassays in Clostridium difficile infection. Am J Gastroenterol. 2009;104(8):2035-41.

18. Dubberke ER, Han Z, Bobo L, Hink T, Lawrence B, Copper S, Hoppe-Bauer J, Burnham CA, Dunne WM Jr. Impact of clinical symptoms on interpretation of diagnostic assays for Clostridium difficile infections. J Clin Microbiol. 2011;49(8):2887-93.

19. Debast SB, Bauer MP, Kuijper EJ. European Society of Clinical Microbiology and Infectious Diseases: update of the treatment guidance document for Clostridium difficile infection. Clin Microbiol Infect. 2014;20(Suppl 2):1-26.

20. Akbari M, Vodonos A, Silva G, Wungjiranirun $M$, Leffler DA, Kelly CP, Novack V. The impact of PCR on Clostridium difficile detection and clinical outcomes. J Med Microbiol. 2015;64(9):1082-6.

21. Alcala L, Martin A, Marin M, Sanchez-Somolinos M, Catalan P, Pelaez $T$, Bouza $E$. The undiagnosed cases of Clostridium difficile infection in a whole nation: where is the problem? Clin Microbiol Infect. 2012;18(7):E204-13.

22. Alcala L, Reigadas E, Marin M, Martin A, Catalan P, Bouza E. Impact of clinical awareness and diagnostic tests on the underdiagnosis of Clostridium difficile infection. Eur J Clin Microbiol Infect Dis. 2015:34(8):1515-25.

23. Examen microbiologique des selles. In: Référentiel en microbiologie médicale (REMIC), Chapter 15. Paris, France: Sociéte Française de Microbiologie 4ème Ed; 2010. p. 105-10.

24. Davies K, Davis G, Barbut F, Eckert C, Petrosillo N, Wilcox MH. Variability in testing policies and impact on reported Clostridium difficile infection rates: results from the pilot longitudinal European Clostridium difficile infection diagnosis surveillance study (LuCID). Eur J Clin Microbiol Infect Dis. 2016;35(12):1949-56.

25. Novak-Weekley SM, Marlowe EM, Miller JM, Cumpio J, Nomura JH, Vance $\mathrm{PH}$, Weissfeld A. Clostridium difficile testing in the clinical laboratory by use of multiple testing algorithms. J Clin Microbiol. 2010;48(3):889-93.

26. Tenover FC, Novak-Weekley S, Woods CW, Peterson LR, Davis T, Schreckenberger P, Fang FC, Dascal A, Gerding DN, Nomura JH, et al. Impact of strain type on detection of toxigenic Clostridium difficile: comparison of molecular diagnostic and enzyme immunoassay approaches. J Clin Microbiol. 2010;48(10):3719-24.

27. Eckert C, Coignard B, Hebert M, Tarnaud C, Tessier C, Lemire A, Burghoffer B, Noel D, Barbut F. Clinical and microbiological features of Clostridium difficile infections in France: the ICD-RAISIN 2009 national survey. Med Mal Infect. 2013:43(2):67-74.

28. Archibald LK, Banerjee SN, Jarvis WR. Secular trends in hospital-acquired Clostridium difficile disease in the United States, 1987-2001.J Infect Dis. 2004;189(9):1585-9.

29. McDonald LC, Owings M, Jernigan DB. Clostridium difficile infection in patients discharged from US short-stay hospitals, 1996-2003. Emerg Infect Dis. 2006:12(3):409-15.

30. Pepin J, Valiquette L, Alary ME, Villemure P, Pelletier A, Forget K, Pepin $\mathrm{K}$, Chouinard D. Clostridium difficile-associated diarrhea in a region of Quebec from 1991 to 2003: a changing pattern of disease severity. CMAJ. 2004:171(5):466-72.

31. Polgreen PM, Yang M, Bohnett LC, Cavanaugh JE. A time-series analysis of Clostridium difficile and its seasonal association with influenza. Infect Control Hosp Epidemiol. 2010:31(4):382-7.
Ready to submit your research? Choose BMC and benefit from:

- fast, convenient online submission

- thorough peer review by experienced researchers in your field

- rapid publication on acceptance

- support for research data, including large and complex data types

- gold Open Access which fosters wider collaboration and increased citations

- maximum visibility for your research: over 100M website views per year

At BMC, research is always in progress.

Learn more biomedcentral.com/submissions 